\title{
Non-Invasive Pressure Support Ventilation in Major Lung Resection for High Risk Patients: Does It Matter?
}

\author{
Bernhard C. Danner ${ }^{1 *}$, Wolfgang Koerber ${ }^{2 *}$, Alexander Emmert ${ }^{1}$, Ulrike Olgemoeller $^{3}$, \\ Hilmar Doerge $^{1}$, Michael Quintel ${ }^{3}$, Carl-P. Criée ${ }^{2}$, Friedrich A. Schoendube ${ }^{1}$ \\ ${ }^{1}$ Department of Thoracic and Cardiovascular Surgery, University Medical Centre Göttingen, Göttingen, Germany; ${ }^{2}$ Department of \\ Pneumology, Respiratory Care and Sleep Medicine, Evangelical Hospital Weende, Göttingen, Germany; ${ }^{3}$ Department of Anaes- \\ thesiology, Emergency and Intensive Care, University Medical Centre Göttingen, Göttingen, Germany. \\ Email: bernd.danner@med.uni-goettingen.de
}

Received May 21 ${ }^{\text {st }}, 2012$; revised June $25^{\text {th }}, 2012$; accepted July $24^{\text {th }}, 2012$

\begin{abstract}
Background and purpose: Patients with severely impaired pulmonary function have an increased operative risk for major lung resection. The clinical benefits of pre- and perioperative, non-invasive pressure support ventilation (NIPSV) have up to now not been extensively evaluated. Patients with severely reduced pulmonary function were investigated in this prospective and randomised single centre clinical trial. Methods: Standard pulmonary evaluation was performed in all patients before major lung resection. To predict postoperative pulmonary function, a lung perfusion-ventilation scan was carried out. All patients enrolled in the study were instructed preoperatively on how to use a NIPSV respirator. After lung resection patients were randomised either for continuation of NIPSV or for standard treatment. Results: Of the 52 patients assessed, 21 patients met the inclusion criteria for the study protocol. Predicted mean postoperative FEV $_{1}$ was $1.10 \mathrm{~L}$ (range $0.92-1.27 \mathrm{~L}$ ). Lobectomy was performed in 14 patients, pneumonectomy in 6 patients and a segmentectomy in 1 patient. No inhospital deaths occurred. Pulmonary complications (reintubation, pneumonia) were more frequent in the NIPSV group than in the control group ( 3 patients versus 1 patient), without statistical significance $(\mathrm{p}=$ 0.31). Conclusions: We observed no mortality and a low morbidity in this high risk group. Postoperative continuation of NIPSV had no beneficial effect on the clinical outcome. Preoperative conditioning with NIPSV, however, seems to be a suitable tool for patients with severely impaired pulmonary function. This study may serve therefore as basis for further investigations for the potential clinical benefits of prophylactic NIPSV in major lung surgery.
\end{abstract}

Keywords: Chronic Obstructive Lung Disease; Clinical Trial; Non-Invasive Positive-Pressure Ventilation; Thoracic Surgery

\section{Introduction}

In major lung surgery, postoperative mortality for pneumonectomy is approximately $11.5 \%$ and for lobectomy $4 \%$ [1]. Decrease in the mortality rate in recent years is mainly a consequence of lower rates of pneumonectomy [2]. Nevertheless, pneumonia and acute respiretory failure are the main causes of postoperative death in about $46 \%$ of patients [2]. Especially in patients with reduced forced expiratory volume at one second $\left(\mathrm{FEV}_{1}\right)$ and diffusing lung capacity for carbon monoxide (DL$\mathrm{CO}$ ), postoperative mortality and morbidity increases inversely proportional to lung function [3-7]. Non-invasive pressure support ventilation (NIPSV) is a mode of mechanical ventilation without endotracheal intubation [8]. Either a certain tidal volume (volume controlled modus) or a maximal inspiratory pressure (pressure con

*Authors contributed equally to this work. trolled modus) is applied via a facial or nasal mask. In the volume controlled modus the ventilator determines the inspiratory pressure, whereas in the pressure controlled modus the tidal volume is determined by the ventilator depending on the pulmonary compliance. During the inspiratory cycle a full respiratory support to patient given. Application of a positive end-expiratory pressure (PEEP) results in a bilevel positive airway pressure mode. NIPSV has several advantages: avoidance of endotracheal intubation and consecutive analgesic sedation with its hemodynamic deterioration; presservation of daily activities as swallowing, coughing, and mobility; reducetion of potential morbidity such as nosocomial pneumonia and upper airway trauma [9]. Especially for exacerbation of severe chronic obstructive pulmonary disease (COPD) it has been found to be superior [10,11]. In thoracic surgery NIPSV has therapeutic benefits for acute respiratory failure after major lung resection, consecu- 
tively reducing mortality [12]. In using as a prophylaxis, NIPSV was found to improve functional lung parameters and arterial oxygenation $[13,14]$. Nevertheless, there are potential adverse side effects, e.g. hemodynamic impairment, aspiration, discomfort and pneumothorax [9].

Smokers are at high risk for bronchial carcinoma and the development of COPD [15]. Patients with indication for major lung resection and severe COPD are challenging in perioperative management [3]. Postoperative pneumonia and acute respiratory failure are main causes of death in patients with severe COPD [16]. To date, there are no clinical concepts to reduce these fatal complications in a prophylactic manner. Only limited data are available on clinical outcome and the prophylactic use of NIPSV in patients with severely impaired pulmonary function who undergo major lung resection. Therefore, we conducted a prospective clinical trial to investigate the effects of NIPSV in this high risk patient population. The aim of the study was to include only patients with persistent severely reduced pulmonary function after maximal conservative therapy.

\section{Patients and Methods}

All patients were presented in our comprehensive thoracic tumour board, consisting of pulmonologists, thoracic surgeons, medical and radiation oncologists. For each patient a therapeutic strategy was determined by this interdisciplinary team approach. Patients with severely impaired pulmonary function and indication for major lung resection were assessed for eligibility for the study protocol.

\subsection{Study Protocol}

All spirometric data were analysed after a post-bronchodilator test. Maximal medication comprising $\beta 2$-agonist, anticholinergics, corticosteroids, theophylline and antibiotics were given for amelioration of the severely impaired pulmonary function. Repeated spirometry was carried out for optimisation of medical treatment. When functional parameters remained severely impaired, indicating a persistent high risk profile according to the British Thoracic Society guidelines [17], patients were included in the study protocol. The main inclusion criterion was a predicted postoperative (ppo) $\mathrm{FEV}_{1}$ between 0.9 $1.2 \mathrm{~L}$. Exclusion criteria were $\mathrm{FEV}_{1}$ under $0.9 \mathrm{~L}$, maximal oxygen uptake lower than $10 \mathrm{ml}$ per min per kg body weight, unstable coronary artery disease, preoperative necessity for invasive ventilation and a Karnofsky index of less than $60 \%$. The preoperative NIPSV protocol was applied in all patients who were then transferred to the thoracic surgery unit. After major lung resection and extubation, patients were prospectively randomised either for continuation of NIPSV (NIPSV group) or for stan- dard care (control group). The ethics committee of the university medical centre of Göttingen approved the study and informed consent of all patients was obtained (German clinical trial registry DRKS-ID 00000311).

\subsection{NIPSV Protocol}

For pulmonary conditioning all patients were instructed in use of non-invasive pressure support ventilation (NIPSV) before undergoing lung resection. A non-invasive ventilator (VS Ultra, Take Air Medical, Bremen, Germany) was used either in a pressure or a volumecontrolled mode as the patient found most comfortable and $85 \%$ favoured the pressure-controlled mode. A nasal mask or a facial mask was adjusted. Tidal volume, maximum inspiration pressure, positive end expiratory pressure and ventilation frequency was adjusted individually to reach normocapnia and an oxygen saturation of more than $92 \%$. After instruction and adaption under hospital conditions, the patients used NIPSV autonomously, applying it for a mean of $5.3 \pm 3.2$ hours per day preoperatively. Tidal volume was mean $8.3 \mathrm{ml}$ per $\mathrm{kg}$, the maximum pressure at a mean level of 16 mbar, and respirator frequency was mean 17 breaths per min. Mean inspiration time was 1.2 seconds, and four patients received a positive end expiratory pressure of 4 mbar. Additionally, all patients underwent an extended physiotherapeutic and medical optimising program. Postoperatively, after randomisation NIPSV was utilised by the patients autonomously and they were instructed to use the ventilator for 10 hours (intermittent or continuous) in the course of two consecutive days and for another 6 hours on the third day. In the control group patients were instructed not to use NIPSV; however, its use was not totally restricted due to ethical considerations.

\subsection{Pulmonary Function Assessment}

For evaluation a lung perfusion-ventilation scan was performed to calculate ppoFEV $\mathrm{F}_{1}$ using the equation: ppo$\mathrm{FEV}_{1}=$ preoperative $\mathrm{FEV}_{1} \times$ (1-proportion of perfused lung area to be resected) $[17,18]$. PH and blood gas measurements were quantified using a Ciba Corning blood gas analyser 855 (Ciba Corning Diagnostics, Medfield, USA). Further testing included evaluation of cardiopulmonary fitness by spiroergometry as well as respiratory muscle testing, diffusing capacity for carbon monoxide (DLCO) and arterial blood gas analysis on room air. For respiratory muscle testing (measurement of $\mathrm{PI}_{\max }(\mathrm{kpa}), \mathrm{P}_{0.1}(\mathrm{kpa})$, and $\mathrm{P}_{0.1} / \mathrm{P}_{\max }(\%)$, respectively), a ZAN 400 and for spiroergometry a ZAN 600 (nSpirehealth, Oberthulba, Germany) were used. The range of normal values was defined according to the recommenddations of the German Airway League and the ATS/ERS statement on respiratory muscle testing $[19,20]$ as $\mathrm{P}_{0.1}$ 
$0.1-0.15 \mathrm{kpa}$, and $\mathrm{PI}_{\max } 8.5 \mathrm{kpa}$ for women and $11.5 \mathrm{kpa}$ for men. Relevant fatigue of the inspiratory muscles was considered present at a $\mathrm{PI}_{\max }$ of $7 \mathrm{kpa}$ for women and 8 kpa for men.

\subsection{Perioperative Care}

Surgery was performed under standardised conditions by antero-axillary or antero-lateral thoracotomy. For pain management, an epidural catheter was the main method for analgesia; alternatively, a percutaneous blood pump was applied. Extubation was performed in accordance with the guidelines of the American College of Chest Physicians [21] either in the operating theatre or in the intensive care unit (ICU). Arterial and venous blood gas analyses, heart and respiratory rate, blood pressure and blood lactate concentration were measured every 4 hours after admission to the ICU. Laboratory blood tests, vital parameters and procedure-related measurements were carried out daily. Pain was measured four times per day on the basis of the analogue pain scale (range 0 to 10). All patients received standardised postoperative management including pain control, chest physiotherapy, early mobilisation and breathing exercises.

\subsection{Randomisation}

Randomisation was done by having the patients of the study group draw from prepared, sealed envelopes. Immediately afterward, the lung resection patients were randomly assigned to the NIPSV group or to the control group.

\subsection{Definition of Endpoints}

Primary endpoint was defined as pulmonary complications, including tracheal reintubation, inhospital death and pneumonia. Inhospital mortality was defined as death during periprocedural stay or within 30 days. Patients were defined as having postoperative pneumonia if they met the criteria set by the Centres of Disease Control and Prevention for nosocomial pneumonia after surgery: these are 1) presence of new and persistent lung infiltrate or 2) purulent tracheal secretion with positive microbial findings $[22,23]$. Reintubation was performed when one major criterion (respiratory arrest, respiratory pauses with loss of consciousness or gasping respiration) or two minor criteria $(20 \%$ increase in arterial carbon dioxide tension, respiratory acidosis under $\mathrm{pH} 7.3$, tachypnoe over 25 breathes per minute, respiratory fatigue or hemodynamic instability) were fulfilled. Secondary endpoints were length of stay at the intensive care unit (ICU), the normal ward of the department of thoracic surgery and total inhospital stay.

\subsection{Statistics}

The data are presented as mean with standard deviation for continuous variables, for categorical variables as proportion (\%) or number (n). Differences in continuous variables were analysed by the Mann Whitney U-Test, in cases of equal variances by the independent t-test. For categorical variables the Fisher's exact test was used. For comparing between groups and at different times, a repeated analysis of variance (ANOVA) was performed. Results were considered significant if $p$ values were 0.05 or less. Assuming that NIPSV is highly effective, already a sample size of 10 patients would reveal a power of $80 \%$. For statistical analysis the SPSS $^{\circledR}$ statistical software (SPSS 15.0 for Windows Evaluation Version, SPSS Inc., Chicago, Illinois, United States) was used.

\section{Results}

\subsection{Preoperative Assessment}

From 52 patients assessed for eligibility, 31 patients did not meet the inclusion criteria or refused to participate. Of the 21 patients in whom the inclusion criteria were met, 10 were randomly selected for the NIPSV group and 11 for the control group. Patients were recruited between April 2005 and June 2009.

Overall mean absolute ppoFEV $\mathrm{F}_{1}$ was $1.11 \pm 0.1 \mathrm{~L}$ and mean relative ppoFEV 1 was $42.1 \% \pm 9.5 \%$. Preoperative data for the NIPSV and control groups are given in Table 1 (clinical characteristics) and Table 2 (cardiopulmonary function). There were no differences between the groups, except for the relative $\mathrm{FEV}_{1}$ value and subsequently the ppoFEV ${ }_{1}$ and the predictive postoperative product (PPP), as well as age (Tables $\mathbf{1}$ and $\mathbf{3}$ ).

\subsection{Postoperative Data}

Measurements of blood gas exchange, vital parameters, chest tube duration and drainage, analogue pain scale, laboratory blood tests, renal function, oxygen consumption or the need for catecholamine did not show a significant difference between the two groups. Blood gas analyses did not differ between the NIPSV or control group, neither between the groups nor between different time points. Oxygen delivery was unrestricted and blood gas exchange was measured according to the time intervals as stated above, independent of NIPSV utilisation. The use of NIPSV in each of the groups was significantly different in accordance with the study protocol. In Table 4, a synopsis of postoperative data measurement is shown.

\subsection{Primary and Secondary Endpoints}

No inhospital death occurred. Overall pulmonary complications were observed in 4 patients (19\%) and were seen more often in the NIPSV group (3 patients, 30\%) 
Table 1. Clinical characteristics.

\begin{tabular}{|c|c|c|c|}
\hline Clinical characteristics & $\begin{array}{l}\text { NIPSV } \\
\mathrm{n}=10\end{array}$ & $\begin{array}{c}\text { Control group } \\
\mathrm{n}=11\end{array}$ & p-value \\
\hline Age (years) & $71.1 \pm 7.7$ & $63.4 \pm 5.9$ & 0.016 \\
\hline Female gender (n) & $3(30 \%)$ & $2(18 \%)$ & 0.635 \\
\hline Body mass index $\left(\mathrm{kg} \cdot \mathrm{m}^{-2}\right)$ & $29.4 \pm 8.1$ & $25.4 \pm 5.4$ & 0.223 \\
\hline Arterial hypertension & $6(60 \%)$ & $5(45 \%)$ & 0.670 \\
\hline Coronary artery disease & $2(20 \%)$ & $5(45 \%)$ & 0.361 \\
\hline Left ventricular function (ejection fraction \%) & $57.2 \pm 10.8$ & $48.7 \pm 10.6$ & 0.340 \\
\hline Diabetes mellitus & $2(20 \%)$ & $3(27 \%)$ & 1.000 \\
\hline $\begin{array}{l}\text { Creatinine kinase }\left(\mathrm{mmol} \cdot 1^{-1}\right) \\
\left(\mathrm{mg} \cdot \mathrm{dl}^{-1}\right)\end{array}$ & $\begin{array}{l}83.1 \pm 29.1 \\
0.94 \pm 0.33\end{array}$ & $\begin{array}{l}88.4 \pm 17.7 \\
1.00 \pm 0.20\end{array}$ & 0.222 \\
\hline Previous thoracic surgery & $1(10 \%)$ & $1(9 \%)$ & 1.000 \\
\hline Karnofsky index (\%) & $80.0 \pm 10.5$ & $82.7 \pm 9.0$ & 0.546 \\
\hline Oncologic disease & $9(90 \%)$ & $11(100 \%)$ & 0.476 \\
\hline \multicolumn{4}{|l|}{ Chronic obstructive pulmonary disease (GOLD Classification) } \\
\hline Stage 1 & $3(30 \%)$ & $0(0 \%)$ & \\
\hline Stage 2 & $5(50 \%)$ & $8(73 \%)$ & \\
\hline Stage 3 & $2(20 \%)$ & $3(27 \%)$ & 0.222 \\
\hline Nicotine consumption (pack years ${ }^{-1}$ ) & $40.0 \pm 20.7$ & $35.7 \pm 12.3$ & 0.738 \\
\hline \multicolumn{4}{|l|}{ Type of surgery } \\
\hline Pneumonectomy & $3(30 \%)$ & $3(27 \%)$ & \\
\hline Bi- or Lobectomy & $7(70 \%)$ & $7(64 \%)$ & \\
\hline Segmentectomy & $0(0 \%)$ & $1(9 \%)$ & 1.000 \\
\hline Extended surgical procedures & $5(50 \%)$ & $5(45 \%)$ & 1.000 \\
\hline Operation time (min) & $185 \pm 31$ & $117 \pm 38$ & 0.467 \\
\hline Single lung ventilation (min) & $90 \pm 22$ & $84 \pm 46$ & 0.799 \\
\hline Thoracic epidural analgesia & $6(60 \%)$ & $7(64 \%)$ & 1.000 \\
\hline
\end{tabular}

Table 2. Preoperative functional parameters.

\begin{tabular}{|c|c|c|c|}
\hline Preoperative functional parameters & NIPSV $n=10$ & Control group $n=11$ & p-value \\
\hline \multicolumn{4}{|l|}{ Arterial blood gases (room air) } \\
\hline $\mathrm{pH}$ & $7.43 \pm 0.03$ & $7.43 \pm 0.03$ & 0.826 \\
\hline $\mathrm{PaO}_{2}(\mathrm{kPa})$ & $9.5 \pm 1.4$ & $8.5 \pm 1.2$ & 0.152 \\
\hline$(\mathrm{mmHg})$ & $71.7 \pm 10.7$ & $64.1 \pm 8.7$ & \\
\hline $\mathrm{PaCO}_{2}(\mathrm{kPa})$ & $5.1 \pm 0.5$ & $5.1 \pm .5$ & 0.668 \\
\hline $\mathrm{mmHg})$ & $38.6 \pm 3.5$ & $38.5 \pm 4.0$ & \\
\hline Vital capacity (litres) & $2.45 \pm 0.67$ & $2.77 \pm 0.95$ & 0.323 \\
\hline Vital capacity $(\%)$ & $68.9 \pm 12.2$ & $67.2 \pm 16.2$ & 0.717 \\
\hline Residual volume (litres) & $3.00 \pm .088$ & $3.70 \pm 1.52$ & 0.323 \\
\hline Residual volume (\%) & $120.7 \pm 30.5$ & $167.1 \pm 63.2$ & 0.081 \\
\hline $\mathrm{FEV}_{1}$ (litres) & $1.49 \pm 0.28$ & $1.37 \pm 0.21$ & 0.257 \\
\hline $\mathrm{FEV}_{1}(\%)$ & $60.2 \pm 11.1$ & $46.8 \pm 10.4$ & 0.021 \\
\hline \multicolumn{4}{|l|}{ Maximum oxygen uptake } \\
\hline $\mathrm{ml} \cdot \mathrm{kg}^{-1} \cdot \min ^{-1}$ & $17.1 \pm 4.9$ & $15.4 \pm 3.8$ & 0.364 \\
\hline$\%$ & $58.7 \pm 15.7$ & $58.9 \pm 10.1$ & 0.793 \\
\hline $\operatorname{DLCO}\left(\mathrm{mmol} \cdot \mathrm{min}^{-1} \cdot \mathrm{kPa}^{-1}\right)$ & $5.1 \pm 1.2$ & $4.9 \pm 1.7$ & 0.563 \\
\hline $\operatorname{DLCO}(\%)$ & $64.3 \pm 15.6$ & $54.8 \pm 17.8$ & 0.283 \\
\hline $\mathrm{PI}_{\max }(\mathrm{kPa})$ & $5.8 \pm 1.5$ & $4.7 \pm 2.8$ & 0.165 \\
\hline $\mathrm{P}_{0.1} \cdot \mathrm{PI}_{\max }{ }^{-1}(\%)$ & $11.2 \pm 10.7$ & $11.0 \pm 6.0$ & 0.667 \\
\hline
\end{tabular}

Abbreviations: $\mathrm{PaO}_{2}=$ arterial oxygen tension; $\mathrm{PaCO}_{2}=$ arterial carbon dioxide tension, $\mathrm{FEV}_{1}=$ forced expiratory volume at 1 second; DLCO = diffusing capacity for carbon monoxide; $\mathrm{P}_{0.1}=$ airway pressure at 0.1 second; $\mathrm{PI}_{\max }=$ maximum inspiratory pressure. 
Table 3. Predicted postoperative functional parameters.

\begin{tabular}{|c|c|c|c|}
\hline Postoperative predicted values & NIPSV $n=10$ & Control group $\mathrm{n}=11$ & p-value \\
\hline V/Q Scan-Proportion resected (\%) & $19.2 \pm 11.8$ & $20.2 \pm 8.9$ & 0.512 \\
\hline \multicolumn{4}{|l|}{ Predicted FEV 1} \\
\hline litres & $1.15 \pm 0.91$ & $1.08 \pm 0.11$ & 0.230 \\
\hline$\%$ & $48.7 \pm 8.9$ & $36.7 \pm 6.3$ & 0.004 \\
\hline \multicolumn{4}{|l|}{ Predicted DLCO } \\
\hline $\mathrm{mmol} \cdot \mathrm{min}^{-1} \cdot \mathrm{kPa}^{-1}$ & $4.00 \pm 1.00$ & $3.98 \pm 1.14$ & 0.888 \\
\hline$\%$ & $51.7 \pm 13.8$ & $44.6 \pm 12.4$ & 0.515 \\
\hline \multicolumn{4}{|l|}{ Predicted Vital capacity } \\
\hline litres & $1.96 \pm 0.59$ & $2.22 \pm 0.88$ & 0.654 \\
\hline$\%$ & $55.6 \pm 12.9$ & $52.8 \pm 10.0$ & 0.756 \\
\hline \multicolumn{4}{|l|}{ Predicted postoperative product } \\
\hline$\left(\operatorname{ppoFEV}_{1} \% \cdot \operatorname{ppoDLCO} \%\right)$ & $2566 \pm 769$ & $1661 \pm 517$ & 0.015 \\
\hline \multicolumn{4}{|l|}{ Predicted maximal oxygen uptake } \\
\hline $\mathrm{ml} \cdot \mathrm{kg}^{-1} \cdot \min ^{-1}$ & $14.2 \pm 4.9$ & $12.1 \pm 2.9$ & 0.475 \\
\hline$(\%)$ & $47.5 \pm 11.9$ & $46.1 \pm 7.2$ & 0.475 \\
\hline
\end{tabular}

Abbreviations: $\mathrm{PaO}_{2}=$ arterial oxygen tension; $\mathrm{PaCO}_{2}=$ arterial carbon dioxide tension, $\mathrm{FEV}_{1}=$ forced expiratory volume at 1 second; DLCO $=$ diffusing capacity for carbon monoxide; $\mathrm{P}_{0.1}=$ airway pressure at 0.1 second; $\mathrm{PI}_{\max }=$ maximum inspiratory pressure, $\mathrm{V} / \mathrm{Q}=$ ventilation $/$ perfusion..

Table 4. Measurements of postoperative data.

\begin{tabular}{|c|c|c|c|c|}
\hline \multicolumn{2}{|c|}{ Postoperative data } & NIPSV $\mathrm{n}=10$ & Control group $\mathrm{n}=11$ & p-value \\
\hline \multicolumn{5}{|c|}{ Oxygen application $\left(\right.$ litres $\cdot$ minute $^{-1}$ ) } \\
\hline Day 0 & & $4.7 \pm 2.4$ & $6.2 \pm 3.5$ & 0.439 \\
\hline Day 1 & & $3.6 \pm 2.3$ & $3.1 \pm 3.0$ & 0.503 \\
\hline Day 2 & & $3.1 \pm 1.8$ & $3.7 \pm 3.7$ & 0.793 \\
\hline \multicolumn{5}{|c|}{ Analogue Pain Scale (0-10) } \\
\hline \multirow[t]{4}{*}{ Day0 } & Time 1 & $2.0 \pm 1.6$ & $2.9 \pm 1.5$ & 0.180 \\
\hline & Time 2 & $2.9 \pm 1.5$ & $4.0 \pm 1.8$ & 0.158 \\
\hline & Time 3 & $2.6 \pm 1.2$ & $3.6 \pm 1.1$ & 0.057 \\
\hline & Time 4 & $2.3 \pm 1.3$ & $3.5 \pm 2.1$ & 0.112 \\
\hline \multirow[t]{4}{*}{ Day1 } & Time 1 & $2.8 \pm 0.9$ & $3.0 \pm 1.1$ & 0.834 \\
\hline & Time 2 & $3.1 \pm 0.8$ & $3.3 \pm 1.1$ & 0.860 \\
\hline & Time 3 & $3.2 \pm 1.0$ & $3.4 \pm 1.1$ & 0.804 \\
\hline & Time 4 & $3.0 \pm 0.7$ & $3.0 \pm 1.2$ & 0.827 \\
\hline \multirow[t]{5}{*}{ Day2 } & Time 1 & $2.3 \pm 0.5$ & $3.1 \pm 1.9$ & 0.395 \\
\hline & Time 2 & $2.8 \pm 0.8$ & $3.2 \pm 1.0$ & 0.403 \\
\hline & Time 3 & $2.7 \pm 0.7$ & $2.9 \pm 0.9$ & 0.704 \\
\hline & Time 4 & $2.5 \pm 0.8$ & $2.6 \pm 07$ & 0.893 \\
\hline & ube (days) & $5.0 \pm 4.0$ & $5.5 \pm 2.9$ & 0.863 \\
\hline \multicolumn{5}{|c|}{ NIPSV postoperative (hours $\cdot$ day $^{-1}$ ) } \\
\hline Day 0 & (day of surgery) & $6.8 \pm 5.5$ & $0.6 \pm 1.4$ & $<0.001$ \\
\hline Day 1 & & $7.7 \pm 3.9$ & $0.4 \pm 0.9$ & 0.002 \\
\hline Day 2 & & $5.9 \pm 4.1$ & $0.4 \pm 1.0$ & 0.001 \\
\hline Total & & $25.6 \pm 14.8$ & $2.2 \pm 3.8$ & $<0.001$ \\
\hline
\end{tabular}

Abbreviations: NIPSV=Non-invasive pressure support ventilation. 
versus the control group (1 patient, 9\%), but the difference was insignificant $(p=0.31)$. Tracheal reintubation due to respiratory insufficiency was necessary in 2 patients of the NIPSV group versus 1 patient in the control group. Nosocomial pneumonia occurred in 3 patients in the NIPSV group. Length of stay at the intensive care unit, length of stay at normal ward and total length of hospital stay (including rehabilitation) was not different between the two groups. All primary and secondary endpoint parameters are presented in Table 5.

Patients who underwent reintubation could be weaned from respirator and discharged from the hospital. Unsurprisingly, the mean time of hospital stay was significantly longer in these cases compared to uncomplicated cases $(48.5 \pm 13.7$ versus $18.2 \pm 9.7$ days, $\mathrm{p}=0.002)$. Prediction of pulmonary complications by the functional pulmonary parameters (see Table 3) failed, whereas pulmonary complications were significantly associated with a longer operation time (220 versus $172 \mathrm{~min}, \mathrm{p}=$ 0.009).

\section{Discussion}

Extensive lung function assessment for patients with a higher risk of major lung resection is recommended by guidelines $[4,17]$ and decreases postoperative morbidity and mortality [24]. Poor pulmonary function parametersare strongly correlated with increased postoperative morbidity and mortality [1,25-27]. In prospective studies, even with good pulmonary function the mortality rate for major lung resection was $2.7 \%-4 \%$ and morbidity rate was up to $41 \%$. In these studies, measurement of immediate postoperative pulmonary function was $11 \%$ less than predicted, indicating an additional postoperative worsening, and improvement was seen after a period of 3 months for lobectomy only $[28,29]$.

In major lung resection NIPSV has a positive effect on surrogate parameters, showing improved gas exchange, as well as on recruitment of atelectasis $[13,14]$. In patients with severely impaired cardio-pulmonary function the effects of prophylactic pre- and postoperative use of NIPSV on clinical outcome have not been previously investigated. Therefore, we conducted this randomised clinical trial to evaluate the potential beneficial effects of these surrogate parameters on overall clinical outcome, especially considering pulmonary complications.

There are several advantages to the use of NIPSV preoperatively. First, in a stressful situation such as acute dyspnoea, nasal or facial masks are not well tolerated, with a patient refusal rate of approximately $34 \%$ [30]. Preoperative introduction, training and familiarisation with ventilator support makes patients confident when using the mask even in uncomfortable circumstances. Second, NIPSV is superior to continuous positive airway pressure for preventing atelectasis [31], and furthermore, pulmonary functional parameters, especially oxygenation, were found to improve by the use of NIPSV. Although our patients were well instructed in autonomous use of NIPSV, patients generally have to be motivated postoperatively, sometimes intensively, which can result in a

Table 5. Primary and secondary outcome parameters.

\begin{tabular}{|c|c|c|c|c|}
\hline Clinical outcome variable & NIPSV $n=10$ & Control group $n=11$ & Confidence Interval & $\mathrm{p}$-value \\
\hline Pulmonary complications (n) & $3(30 \%)$ & $1(9 \%)$ & $0.4-50.2$ & 0.311 \\
\hline Inhospital death & 0 & 0 & & \\
\hline Reintubation (n) & $2(20 \%)$ & $1(9 \%)$ & $0.2-32.8$ & 0.586 \\
\hline Pneumonia (n) & $3(30 \%)$ & 0 & & 0.090 \\
\hline ICU stay (days) & $1.7 \pm 1.6$ & $2.8 \pm 5.4$ & $-2.6-4.8$ & 0.777 \\
\hline Normal ward stay (days) & $12.6 \pm 3.8$ & $13.7 \pm 5.8$ & $-25.7-4.4$ & 0.723 \\
\hline Hospital-stay (days) & $28.8 \pm 19.9$ & $18.9 \pm 9.0$ & $-3.4-5.7$ & 0.306 \\
\hline
\end{tabular}

Abbreviations: NIPSV $=$ Non-invasive pressure support ventilation, $\mathrm{ICU}=$ Intensive Care Unit, $\mathrm{n}=$ number. 
reduced utilisation time of the ventilator. However, the target overall ventilation time in the NIPSV group was met after 3 days. Possible undesired negative effects such as alterations of hemodynamics, appearance of bronchopleural fistula or bronchial stump insufficiency have to be taken into consideration $[13,14]$, as well as the limited or disputable benefit of surgical resection in expected high operative risk $[32,33]$.

Particularly the group with reduced lung capacity bordering on inoperability was the target group of our investigation. No single parameter for operative risk prediction exists, but there are several recommendations $[4,25,34]$. Severe reduction of $\mathrm{FEV}_{1}$ was the main inclusion criterion for our study. The absolute value was chosen in the planning phase [17]; nowadays, it would be more reasonable to use parameters such as PPP (product of $\mathrm{ppoFEV}_{1} \%$ and ppoDLCO $\%$ ) which take both main predictors into account. Hence, the lower the PPP, the higher the operative risk probability [6]. Despite randomisation, the NIPSV group had improved pulmonary parameters (ppoFEV ${ }_{1}$ and PPP) and the patients were older compared to the control group. The incidence of pneumonia was higher in the NIPSV group, possibly due to the higher mean patient age. In fact, contrary to our hypothesis that postoperative NIPSV has a beneficial effect, other negative side effects of positive pressure ventilation than mentioned above may result in a worse postoperative course. However, the endpoints were not statistically different between the groups. Although the functional parameters in prospective studies were tremendously improved compared to our study, mortality and morbidity remained high $(4 \%$ and $41 \%$, respectively) $[28,29]$. The absence of perioperative death as well as the low morbidity in this high risk patient cohort was possibly due to the preoperative conditioning of the patients for use of NIPSV. This may have already improved pulmonary function, lung compliance and muscle force. Since the pulmonary function parameters were significantly decreased in the control group and the pulmonary complications were low, a beneficial effect of preoperative conditioning with NIPSV seems likely.

Pulmonary function testing to predict postoperative function is extensive and time-consuming, particularly in patients with severely impaired pulmonary function. In retrospective studies, the predicted pulmonary function is inaccurate due to resection of tumourous or non-efficient lung parenchyma, which limits the interpretation of the results for predicting operative risk $[25,35,36]$. To exclude this bias we validated the predicted lung function by a ventilation-perfusion scan. In our study, only patients with accurately evaluated ppoFEV ${ }_{1}$ were included; the majority of patients were excluded because of false underestimation of ppoFEV $V_{1}$ either due to standard (segmental) calculated estimation or to improved $\mathrm{FEV}_{1}$ through intensive pulmonary care. According to statistical power analysis, our study dealt with an adequate number of patients, but allows qualified interpretation of results only for powerful effectiveness of NIPSV. Nevertheless, a higher sample number and a modified study design would most likely provide more conclusive data on the prophylactic use of NIPSV.

\section{Conclusion}

In contrast to the expected operative risk in patients with severely impaired pulmonary function, in our present study pulmonary morbidity was low and no mortality occurred. Although postoperative continuation of NIPSV had no strong effect on the rate of pulmonary complications, preoperative application of NIPSV may have had a positive effect on postoperative outcome. This investigation can serve as a pilot study for an expanded multicentre investigation to evaluate the potential use of NIPSV for decreasing perioperative risk in patients with severely reduced lung function.

\section{REFERENCES}

[1] D. H. Harpole Jr., M. M. DeCamp Jr., J. Daley, K. Hur, C. A. Oprian, W. G. Henderson, et al., "Prognostic Models of Thirty-Day Mortality and Morbidity after Major Pulmonary Resection," The Journal of Thoracic and Cardiovascular Surgery, Vol. 117, No. 5, 1999, pp. 969-979. doi:10.1016/S0022-5223(99)70378-8

[2] S. Watanabe, H. Asamura, K. Suzuki and R. Tsuchiya, "Recent Results of Postoperative Mortality for Surgical Resections in Lung Cancer," The Annals of Thoracic Surgery, Vol. 78, No. 3, 2004, pp. 999-1002. doi:10.1016/j.athoracsur.2004.04.007

[3] C. T. Bolliger, C. Wyser, H. Roser, M. Solèr, A. P. Perruchoud, "Lung Scanning and Exercise Testing for the Prediction of Postoperative Performance in Lung Resection Candidates at Increased Risk for Complications," Chest, Vol. 108, No. 2, 1995, pp. 341-348. doi:10.1378/chest.108.2.341

[4] D. Datta and B. Lahiri, "Preoperative Evaluation of Patients Undergoing Lung Resection Surgery," Chest, Vol. 123, No. 6, 2003, pp. 2096-2103. doi:10.1378/chest.123.6.2096

[5] M. K. Ferguson, L. Little, L. Rizzo, K. J. Popovich, G. F. Glonek, A. Leff, et al., "Diffusing Capacity Predicts Morbidity and Mortality after Pulmonary Resection," The Journal of Thoracic and Cardiovascular Surgery, Vol. 96, No. 6, 1988, pp. 894-900.

[6] R. J. Pierce, J. M. Copland, K. Sharpe and C. E. Barter, "Preoperative Risk Evaluation for Lung Cancer Resection: Predicted Postoperative Product as a Predictor of Surgical Mortality," American Journal of Respiratory and Critical Care Medicine, Vol. 150, No. 4, 1994, pp. 947-955.

[7] J.-S. Wang, R. T. Abboud, K. G. Evans, R. J. Finley and B. L. Graham, "Role of CO Diffusing Capacity during 
Exercise in the Preoperative Evaluation for Lung Resection," American Journal of Respiratory and Critical Care Medicine, Vol. 162, No. 4, 2000, pp. 1435-1444.

[8] R. E. Hillberg and D. C. Johnson, "Noninvasive Ventilation," New England Journal of Medicine, Vol. 337, No. 24, 1997, pp. 1746-1752. doi:10.1056/NEJM199712113372407

[9] T. Liesching, H. Kwok and N. S. Hill, "Acute Applications of Noninvasive Positive Pressure Ventilation," Chest, Vol. 124, No. 2, 2003, pp. 699-713. doi:10.1378/chest.124.2.699

[10] L. Brochard, J. Mancebo, M. Wysocki, F. Lofaso, G. Conti, A. Rauss, et al., "Noninvasive Ventilation for Acute Exacerbations of Chronic Obstructive Pulmonary Disease," New England Journal of Medicine, Vol. 133, No. 13, 1995, pp. 817-822. doi:10.1056/NEJM199509283331301

[11] S. P. Keenan and S. Mehta, "Noninvasive Ventilation for Patients Presenting with Acute Respiratory Failure: The Randomized Controlled Trials," Respiratory Care, Vol. 54, No. 1, 2009, pp. 116-126.

[12] I. Auriant, A. Jallot, P. Hervé, J. Cerrina, L. F. Le Roy, J. L. Fournier, et al., "Noninvasive Ventilation Reduces Mortality in Acute Respiratory Failure Following Lung Resection," American Journal of Respiratory and Critical Care Medicine, Vol. 164, No. 7, 2001, pp. 1231-1235.

[13] R. Aguilo, B. Togores, S. Pons, M. Rubi, F. Barbe and A. G. Agusti, "Noninvasive Ventilatory Support after Lung Resectional Surgery," Chest, Vol. 112, No. 1, 1997, pp. 117-121. doi:10.1378/chest.112.1.117

[14] C. Perrin, V. Jullien, N. Vénissac, F. Berthier, B. Padovani, F. Guillot, et al., "Prophylactic Use of Noninvasive Ventilation in Patients Undergoing Lung Resectional Surgery," Respiratory Medicine, Vol. 101, No. 7, 2007, pp. 1572-1578. doi:10.1016/j.rmed.2006.12.002

[15] E. R. Sutherland and R. M. Cherniack, "Management of Chronic Obstructive Pulmonary Disease," New England Journal of Medicine, Vol. 350, No. 26, 2004, pp. 26892697. doi:10.1056/NEJMra030415

[16] A. Lefebvre, C. Lorut, M. Alifano, H. Dermine, N. Roche, R. Gauzit, et al., "Noninvasive Ventilation for Acute Respiratory Failure after Lung Resection: An Observational Study," Intensive Care Medicine, Vol. 35, No. 4, 2009, pp. 663-670. doi:10.1007/s00134-008-1317-z

[17] British Thoracic Society-Society of Cardiothoracic Surgeons of Great Britain Ireland Working Party, "BTS Guidelines: Guidelines on the Selection of Patients with Lung Cancer for Surgery," Thorax, Vol. 56, No. 2, 2001, pp. 89-108. doi:10.1136/thorax.56.2.89

[18] K. R. Larsen, J. O. Lund, U. G. Svendsen, N. Milman and B. N. Petersen, "Prediction of Post-Operative Cardiopulmonary Function Using Perfusion Scintigraphy in Patients with Bronchogenic Carcinoma," Clinical Physiology, Vol. 17, No. 3, 1997, pp. 257-267. doi:10.1111/j.1365-2281.1997.tb00005.x

[19] American Thoracic Society (ATS) and European Respiratory Society (ERS), "ATS/ERS Statement on Respiratory Muscle Testing," American Journal of Respiratory and Critical Care Medicine, Vol. 166, No. 4, 2002, pp.

\section{8-624. doi:10.1164/rccm.166.4.518}

[20] C.-P. Criée, "Empfehlungen der Deutschen Atemwegsliga zur Messung der inspiratorischen Muskelfunktion [Recommendations of the German Airway League (Deutsche Atemwegsliga) for the Determination of Inspiratory Muscle Function]," Pneumologie, Vol. 57, No. 2, 2003, pp. 98-100. doi:10.1055/s-2003-37154

[21] N. R. MacIntyre, D. J. Cook, E. W. Ely Jr., S. K. Epstein, J. B. Fink, J. E. Heffner, et al., "Evidence-Based Guidelines for Weaning and Discontinuing Ventilatory Support: A Collective Task Force Facilitated by the American College of Chest Physicians; the American Association for Respiratory Care; and the American College of Critical Care Medicine," Chest, Vol. 120, Suppl. 6, 2001, pp. 375S-395S. doi:10.1378/chest.120.6 suppl.375S

[22] A. M. Arozullah, S. F. Khuri, W. G. Henderson, J. Daley and Participants in the National Veterans Affairs Surgical Quality Improvement Program, "Development and Validation of a Multifactorial Risk Index for Predicting Postoperative Pneumonia after Major Noncardiac Surgery," Annals of Internal Medicine, Vol. 135, No. 10, 2001, pp. 847-857.

[23] J. S. Garner, W. R. Jarvis, T. G. Emori, T. C. Horan and J. M. Hughes, "CDC Definitions for Nosocomial Infections, 1988," AJIC: American Journal of Infection Control, Vol. 16, No. 3, 1988, pp. 128-140. doi:10.1016/0196-6553(88)90053-3

[24] C. Wyser, P. Stulz, M. Solèr, M. Tamm, J. Müller-Brand, J. Habicht, et al., "Prospective Evaluation of an Algorithm for the Functional Assessment of Lung Resection Candidates," American Journal of Respiratory and Critical Care Medicine, Vol. 159, No. 5, 1999, pp. 1450-1456.

[25] F. J. Algar, A. Alvarez, A. Salvatierra, C. Baamonde, J. L. Aranda and F. J. López-Pujol, "Predicting Pulmonary Complications after Pneumonectomy for Lung Cancer," European Journal Cardio-Thoracic Surgery, Vol. 23, No. 2, 2003, pp. 201-208. doi:10.1016/S1010-7940(02)00719-4

[26] M. K. Ferguson, L. B. Reeder and R. Mick, "Optimizing Selection of Patients for Major Lung Resection," The Journal of Thoracic and Cardiovascular Surgery, Vol. 109, No. 2, 1995, pp. 275-281. doi:10.1016/S0022-5223(95)70389-6

[27] P. Bonde, K. McManus, M. McAnespie and J. McGuigan, "Lung Surgery: Identifying the Subgroup at Risk for Sputum Retention," European Journal Cardio-Thoracic Surgery, Vol. 22, No. 1, 2002, pp. 18-22. doi:10.1016/S1010-7940(02)00205-1

[28] A. Bobbio, A. Chetta, E. Internullo, L. Ampollini, P. Carbognani, S. Bettati, et al., "Exercise Capacity Assessment in Patients Undergoing Lung Resection," European Journal Cardio-Thoracic Surgery, Vol. 35, No. 3, 2009, pp. 419-422. doi:10.1016/j.ejcts.2008.11.004

[29] A. Brunelli, M. Refai, M. Salati, F. Xiumé and A Sabbatini, "Predicted versus Observed FEV1 and DLCO after Major Lung Resection: A Prospective Evaluation at Different Postoperative Periods," The Annals of Thoracic Surgery, Vol. 83, No. 3, 2007, pp. 1134-1139. doi:10.1016/j.athoracsur.2006.11.062 
[30] H. Kwok, J. McCormack, R. Cece, J. Houtchens and N. S. Hill, "Controlled Trial of Oronasal versus Nasal Mask Ventilation in the Treatment of Acute Respiratory Failure," Critical Care Medicine, Vol. 31, No. 2, 2003, pp. 468-473. doi:10.1097/01.CCM.0000045563.64187.20

[31] P. Pasquina, P. Merlani, J. M. Granier and B. Ricou, "Continuous Positive Airway Pressure versus Noninvasive Pressure Support Ventilation to Treat Atelectasis after Cardiac Surgery," Anesthesia \& Analgesia, Vol. 99, No. 4, 2004, pp. 1001-1008. doi:10.1213/01.ANE.0000130621.11024.97

[32] S. Sura, E. Yorke, A. Jackson and K. E. Rosenzweig, "High-Dose Radiotherapy for the Treatment of Inoperable Non-Small Cell Lung Cancer," Cancer Journal, Vol. 13, No. 4, 2007, pp. 238-242. doi:10.1097/PPO.0b013e31813ffd7b

[33] N. P. Rowell and C. J. Williams, "Radical Radiotherapy for Stage I/II Non-Small Cell Lung Cancer in Patients Not Sufficiently Fit for or Declining Surgery (Medically
Inoperable)," Cochrane Database of Systematic Reviews (Online), Vol. 2, No. 2, 2001, p. CD002935.

[34] A. Brunelli, A. Charloux, C. T. Bolliger, G. Rocco, J.-P. Sculier, G. Varela, et al., "ERS/ESTS Clinical Guidelines on Fitness for Radical Therapy in Lung Cancer Patients (Surgery and Chemo-Radiotherapy)," European Respiratory Journal, Vol. 34, No. 1, 2009, pp. 17-41. doi:10.1183/09031936.00184308

[35] R. J. Cerfolio, M. S. Allen, V. F. Trastek, C. Deschamps, P. D. Scanlon and P. C. Pairolero, "Lung Resection in Patients with Compromised Pulmonary Function," The Annals of Thoracic Surgery, Vol. 62, No. 2, 1996, pp. 348351. doi:10.1016/0003-4975(96)00231-7

[36] F. Stéphan, S. Boucheseiche, J. Hollande, A. Flahault, A. Cheffi, B. Bazelly, et al., "Pulmonary Complications Following Lung Resection: A Comprehensive Analysis of Incidence and Possible Risk Factors," Chest, Vol. 118, No. 5, 2000, pp. 1263-1270. doi:10.1378/chest.118.5.1263 